\title{
Controlled Comparison of Tetracycline and Furazolidone in Cholera*
}

\author{
N. F. PIERCE, M.D. ; J. G. BANWELL, D.M. ; R. C. MITRA, M.B., B.S.; G. J. CARANASOS, M.D. \\ R. I. KEIMOWITZ, M.D. ; J. THOMAS, M.A. ; A. MONDAL, M.B., CH.B.
}

Brit. med. F., 1968, 3, 277-280

\begin{abstract}
Summary : A controlled comparison of furazolidone and tetracycline in the treatment of cholera indicates that, in either dosage used, furazolidone reduced total stool volume by $50 \%$ and duration of diarrhoea by $40 \%$. These results are comparable to those achieved with tetracycline, which was given in presently recommended dosage. Both furazolidone and tetracycline significantly reduced the rate of stool output within 18 to 24 hours of starting antibiotic treatment. Furazolidone was significantly less effective than tetracycline in rapidly and consistently terminating vibrio excretion. One convalescent carrier of cholera vibrios was identified among control patients; none was identified among patients treated with either tetracycline or furazolidone. All Vibrio cholerae strains tested were sensitive to tetracycline and furazolidone, but larger concentrations of the latter were required to achieve inhibition of growth. It is concluded that tetracycline remains the antibiotic of choice in cholera but that furazolidone would be a useful adjunct to cholera therapy when tetracycline is unobtainable or if strains of $\mathrm{V}$. cholerae with clinically significant resistance to tetracycline should be encountered.
\end{abstract}

\section{Introduction}

Several antibiotics have proved to be valuable adjuncts to the treatment of cholera (Greenough et al., 1964 ; Carpenter et al., 1966 ; Lindenbaum et al., 1968), and tetracycline has been recommended as the antibiotic of choice (Wallace et al., 1968). Despite its clearly proved usefulness tetracycline is expensive in some countries, and there is some evidence that cholera vibrios may develop resistance to it (Lewis, 1967). These limitations have prompted a search for an alternative antibacterial agent of equal therapeutic efficacy and lacking these shortcomings. This paper reports our findings in a controlled study comparing tetracycline with furazolidone, a nitrofurantoin derivative, in the treatment of cholera.

\section{Methods and Materials}

The study was carried out in April to July 1967 and included 65 male patients over the age of 10 years who gave a history of " rice water" diarrhoea of less than 24 hours' duration without previous antibiotic treatment, and who showed evidence of dehydration and hypotension (systolic blood pressure less than $80 \mathrm{~mm}$. $\mathrm{Hg}$ ) when admitted to hospital. Data on 49 patients are presented, the remainder being excluded because of failure to identify Vibrio cholerae in the stool (14 patients) or because of technical errors in performance of the study (two patients). Immediately on admission the patient was weighed and placed on a metabolic bed. A brief physical examination was made, a femoral artery blood specimen obtained, and intravenous fluid replacement promptly started. The intravenous fluid used contained $\mathrm{Na} 154 \mathrm{mEq} / \mathrm{l}, \mathrm{Cl} 103 \mathrm{mEq} / 1$, and lactate

- From the Johns Hopkins University Center for Medical Research and Training, the Infectious Diseases Hospital and the School of Tropical Medicine, Calcutta, India.

This study was supported by research grants $5 \times 4317, \mathrm{AI}-07628-01$, and 5RO7TW00141-07CIC from the United States National Institutes of Health.
$51 \mathrm{mEq} / 1$. , with $\mathrm{KCl}(20 \mathrm{mEq} / 1$.) added after the third litre. A stool specimen for culture was obtained by means of a sterile rectal catheter shortly after admission. Complete rehydration, as judged by normal blood pressure, a full radial pulse at a rate less than 90 per minute, normal skin turgor, and normal plasma specific gravity (1.024-1.027), was accomplished in the first 60 to 90 minutes after entry. Following this all subsequent stool loss was measured and replaced on a volume-for-volume basis with intravenous fluids until diarrhoea ceased.

All stool and urine were collected separately. Measurements of output were made every six hours and also when each new litre of intravenous fluid was started. However, the time of admission did not usually coincide with the beginning of the routine six-hour measurement periods on the ward. To determine output in six-hour periods from admission it was necessary to make a linear interpolation between the closest two measurements preceding and following the end of each six-hour interval after admission. Duration of diarrhoea was determined as the time elapsed from entry until the last passage of any liquid stool.

After the first six hours patients were allowed small amounts of water or green coconut water by mouth. A normal diet was resumed when diarrhoea ceased. All antibiotics were given by mouth, therapy being initiated three to seven hours after admission.

After their selection for study patients were randomly assigned to one of four therapeutic groups. These were: tetracycline $500 \mathrm{mg}$. every six hours for 48 hours ( 8 doses, $4 \mathrm{~g}$.), furazolidone $200 \mathrm{mg}$. every six hours for 72 hours (12 doses, $2.4 \mathrm{~g}$.), furazolidone $400 \mathrm{mg}$. daily for three days (3 doses, $1.2 \mathrm{~g}$.), and a control group receiving no antibiotics.

Liquid stool was obtained at admission and rectal swabs were obtained daily therafter until the patient was discharged. These were cultured directly, after six- to eight-hour alkaline peptone water enrichment, and after 24 hours' enrichment in Selenite-F broth. All specimens were cultured on bile salt agar, meat extract agar, desoxycholate agar, and salmonella-shigella agar. Suspicious colonies were identified by standard biochemical and slide-agglutination techniques. Isolates of $V$. cholerae were designated as El Tor biotype on the basis of resistance to polymyxin B (Gan and Tija, 1963) and to Mukherjee's type IV phage (Mukherjee et al., 1957), and being haemagglutininpositive (Barua and Mukherjee, 1963). Duration of vibrio excretion was calculated as the time (in hours) from entry until the last positive stool culture was obtained. After at least three consecutive daily stool cultures negative for $V$. cholerae and at least three days after discontinuation of antibiotics patients were purged with 45-60 g. of magnesium sulphate given by mouth. Liquid stool remaining in the rectum was collected by a sterile catheter immediately after purging and cultured as above.

Biochemical analysis performed on arterial blood taken at the time of admission included $\mathrm{pH}$ by means of a Radiometer $p \mathrm{H}$ meter with microelectrode, plasma $\mathrm{CO}_{2}$-combining power with a Van Slyke volumetric apparatus, and plasma specific gravity by means of a temperature-corrected total solids meter (American Optical Co.). 
The minimum inhibitory concentration and minimum bactericidal concentrations of tetracycline and furazolidone were determined for 22 of the strains of $V$. cholerae isolated from this group of patients. Standard tube dilution techniques were utilized with modifications as previously described by this laboratory (Lewis and Sanyal, 1965).

\section{Results}

Historical, physical, and laboratory data for each therapeutic group obtained at admission are compared in Table $I$. There was no significant difference between groups in regard to any observation when examined by analysis of variance. Stool outpurt during the first six hours, though less in the tetracycline group, did not differ significantly $(0.05<\mathrm{P}<0.10)$ from the other groups. $V$. cholerae, biotype El Tor, Ogawa, was isolated from each case.

Table I.-Comparison of Groups at Admission and During First Six Hours. Mean for Each Group is Represented with Standard Error of Mean Indicated Beneath. There was no Significant Difference Between Groups in Regard to Any of the Characteristics Compared

\begin{tabular}{|c|c|c|c|c|}
\hline & Control & $\begin{array}{c}\text { Tetracycline } \\
500 \mathrm{mg} \text {. Every } \\
6 \text { Hours } \\
\text { (8 Doses) }\end{array}$ & $\begin{array}{c}\text { Furazolidone } \\
200 \text { mg. Bvery } \\
6 \text { Hours } \\
\text { (12 Doses) }\end{array}$ & $\begin{array}{c}\text { Furazolidone } \\
400 \text { mg. Daily } \\
\text { (for } \\
3 \text { Days) }\end{array}$ \\
\hline $\begin{array}{ll}\text { No. of patients } & . \\
\text { Age (years) } & \ldots \\
\text { Weight (kg.) } & \text {. } \\
\text { Duration before entry }\end{array}$ & $\begin{array}{c}12 \\
38.5 \pm 3.8 \\
42.6 \pm 1.3\end{array}$ & $\begin{array}{c}12 \\
38 \cdot 0 \pm 3 \cdot 5 \\
43 \cdot 4 \pm 1 \cdot 4\end{array}$ & $\begin{array}{c}13 \\
33.5 \pm 4 \cdot 3 \\
40.6 \pm 2 \cdot 6\end{array}$ & $\begin{array}{c}12 \\
35.6 \pm 6.0 \\
39.0 \pm 1.9\end{array}$ \\
\hline (hours) & $14 \cdot 2 \pm 3 \cdot 6$ & $13 \cdot 0 \pm 2 \cdot 0$ & $14 \cdot 2 \pm 2 \cdot 4$ & $12 \cdot 7 \pm 2 \cdot 3$ \\
\hline $\begin{array}{l}\text { Systolic (mm. Hg)... } \\
\text { sure (mm (per min.) } \\
\text { Respirate (per (per min.) } \\
\text { Arterial pH }\end{array}$ & $\begin{array}{c}39 \pm 9 \\
123 \pm 7 \\
30 \pm 1 \cdot 3 \\
7 \cdot 207 \pm 0.020\end{array}$ & $\begin{array}{c}24 \pm 9 \\
142 \pm 5 \\
36 \pm 1.9 \\
7 \cdot 176 \pm 0.023\end{array}$ & $\begin{array}{c}49 \pm 9 \\
118 \pm 6 \\
35 \pm 3 \cdot 5 \\
7 \cdot 145 \pm 0 \cdot 024\end{array}$ & $\begin{array}{c}41 \pm 8 \\
135 \pm 8 \\
40 \pm 4.4 \\
7 \cdot 139 \pm 0 \cdot 021\end{array}$ \\
\hline $\begin{array}{l}\text { Plasma specific } \\
\text { gravity } \ldots\end{array}$ & $1.0399 \pm 0.0008$ & $1.0417 \pm 0.0009$ & $1.0397 \pm 0.0012$ & $1.0414 \pm 0.0008$ \\
\hline $\begin{array}{l}\text { Plasma bicarbonate } \\
\text { (mEq/l.) }\end{array}$ & $8.9 \pm 0.7$ & $6.6 \pm 0.8$ & $8.2 \pm 0.8$ & $8 \cdot 1 \pm 1 \cdot 3$ \\
\hline $\begin{array}{cc}\text { Stool volume } & 1 \text { st } \\
6 \text { hours } & \ldots\end{array}$ & $1,826 \pm 299$ & $1,324 \pm 220$ & $1,890 \pm 228$ & $1,902 \pm 279$ \\
\hline
\end{tabular}

\section{Clinical Course and Vibrio Excretion}

The results of treatment are compared in Table II. Total stool volume and duration of diarrhoea were linearly related to the initial six-hour stool output. In the tetracycline group the initial six-hour stool volume was lower than in the other three $(0.05<\mathrm{P}<0.10)$. It was assumed that this was a chance occurrence in this group and was unrelated to antibiotic therapy which was begun late in the first six-hour period. It was thought necessary to take this initial difference into consideration in comparing the groups. They were therefore compared by analysis of covariance which corrected for the initial differences between them. Total stool volume and duration of diarrhoea were significantly less in each antibiotic treatment group than in controls $(P<0.001$ in each case), but there were no significant differences in these values between antibiotic treatment groups. Duration of cholera vibrio excretion was examined by analysis of variance, no correction being applied. $V$. cholerae excretion was of significantly shorter duration in the tetracycline group (mean 14.5 hours) than in any of the other groups $(P<0.025$ to $<0.0005)$, while with furazolidone (400 mg. daily) the duration of $V$. cholerae excretion was less than controls $(P<0.025)$, but with furazolidone $(200 \mathrm{mg}$. every six hours) it did not differ significantly from the controls. Maximum duration of cholera vibrio excretion was 33 hours with tetracycline, 73 hours with furazolidone $400 \mathrm{mg}$. daily, 164 hours with furazolidone $200 \mathrm{mg}$. every six hours, and 137 hours in controls.

The mean stool output for each group in each six-hour period after admission is shown in the Chart. For each group the decrease in stool output during successive six-hour periods for the first 48 hours can be adequately described by a straight line fitted by the method of least squares ( $r=0.92$ to 0.96 ). The rate of decline in mean six-hour stool output during the
TABLB II.-Comparison of Results of Treatment. Mean of Each Group is Indicated with Standard Error of Mean Beneath. Method of Comparison of Results is Indicated in Text

\begin{tabular}{|c|c|c|c|c|}
\hline & Control & $\begin{array}{c}\text { Tetracycline } \\
500 \mathrm{mg} \text {. Every } \\
6 \text { Hours } \\
\text { (8 Doses) }\end{array}$ & \begin{tabular}{|} 
Furazolidone \\
$200 \mathrm{mg}$. Every \\
6 Hours \\
(12 Doses)
\end{tabular} & $\begin{array}{l}\text { Furazolidone } \\
400 \text { mg. Daily } \\
\text { (for } \\
3 \text { Days) }\end{array}$ \\
\hline $\begin{array}{l}\text { Duration of diarrhoea } \\
\text { (hours) } \\
\text { Total stool volume }\end{array}$ & $75 \cdot 5 \pm 8 \cdot 8$ & $31 \cdot 6 * \pm 2.7$ & $46 \cdot 1 * \pm 6 \cdot 1$ & $49 \cdot 2^{*} \pm 5 \cdot 4$ \\
\hline (litres) of ribrio & 13. & $3.9^{*} \pm 0.6$ & $6 \cdot 8^{*} \pm 1 \cdot 3$ & $7 \cdot 4^{*} \pm 1 \cdot 2$ \\
\hline on (hours) & $71 \cdot 5 \pm 8 \cdot 0$ & $14 \cdot 5^{*}+ \pm 3 \cdot 2$ & $51 \cdot 7 \dagger \pm 11 \cdot 6$ & $40 \cdot 1 * t \pm 7 \cdot 5$ \\
\hline $\begin{array}{l}\text { otal intraveno } \\
\text { fluids (litres) }\end{array}$ & $17 \cdot 8 \pm 2 \cdot 8$ & $8 \cdot 6 * \pm 1 \cdot 0$ & $11 \cdot 8^{*} \pm 1 \cdot 6$ & $12 \cdot 5^{*} \pm 1 \cdot 1$ \\
\hline
\end{tabular}

- Values differing significantly from controls $(P<0.05)$.

+ Values for tetracycline group differing significantly $(P<0.05)$ from either furazolidone group.

first 48 hours after admission is the regression coefficient of each straight line. The mean rates of decline for the three treatment groups (tetracycline, $197 \mathrm{ml} . / 6$ hours ; furazolidone $400 \mathrm{mg}$. daily, $261 \mathrm{ml} . / 6$ hours; and furazolidone $200 \mathrm{mg}$ every 6 hours, $246 \mathrm{ml} . / 6$ hours) did not differ significantly, but each differed significantly $(P<0.05$ to $<0.01)$ from the control group (116 ml./6 hours). In each group the initial six-hour stool output was compared with the output in each following six-hour period. In each treatment group, within 12 to 18 hours after admission (6 to 12 hours after antibiotic treatment), the decrease in stool output was greater than the decrease in output of the control group. However, this difference was not significant. It was not until 24 to 30 hours after admission (18 to 24 hours after starting antibiotic treatment) that the decrease in six-hour stool output for each treatment group was significantly greater than the decrease in output of the controls (tetracycline, $\mathrm{P}<0.05$; both furazolidone groups, $P<0.01$ ).

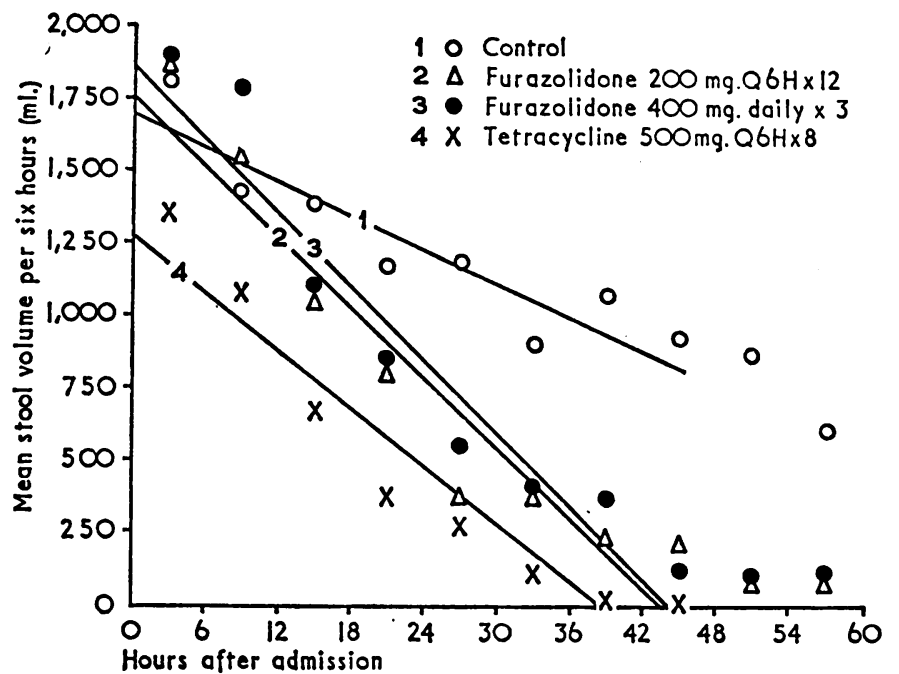

Comparison of effect of furazolidone and tetracycline on rate of stool production. Mean rate of stool production during consecutive six-hour periods from admission is plotted for each treatment group and for controls. For each group the decline in stool output is represented by a straight line fitted by the method of least squares $(r=0.92$ to 0.96$)$. Rate of decline in stool output was : controls, $116 \mathrm{mg} / 6$ hours; tetracycline, of decline in stool output was: controls, 116 mg./61 hours furazolidone $200 \mathrm{mg}$. every six hours, $246 \mathrm{ml} . / 6$ hours.

Forty-three convalescent patients were satisfactorily purged with magnesium sulphate (10 to 12 in each group). One purge was positive for $V$. cholerae, biotype El Tor, Ogawa. This was in a 58-year-old control patient who also had far advanced tuberculosis. Repeated purging in this patient revealed positive cultures on four occasions up to 44 days after admission. Further data on this patient will be reported elsewhere.

Four patients receiving furazolidone vomited. If this occurred within one hour of drug administration the dosage was repeated. No other side-effect of antibiotic treatment was noted. There was no mortality. 


\section{Antibiotic Sensitivity of V. cholerae Isolates}

Table III summarizes the sensitivities of the 22 strains of $V$. cholerae, biotype El Tor, Ogawa, to tetracycline and furazolidone. With tetracycline, inhibition of all strains was accomplished by $4 \mu \mathrm{g} . / \mathrm{ml}$. and killing by $8 \mu \mathrm{g} . / \mathrm{ml}$. However, with furazolidone, inhibition required $16 \mu \mathrm{g} . / \mathrm{ml}$., and killing of 8 of 22 strains was not accomplished by the maximum concentration used, $32 \mu \mathrm{g} . / \mathrm{ml}$. Table III also compares the sensitivities to tetracycline of strains from the present study to those of 77 strains of the same biotype and serotype isolated in Calcutta in 1964 and previously reported from this laboratory (Lewis and Sanyal, 1965). A slight but definite decrease in sensitivity to tetracycline is present in the 1967 strains. Whereas approximately $25 \%$ of the 1964 strains were both inhibited and killed by $1 \mu \mathrm{g}$. of tetracycline per ml., none of the 1967 strains were either inhibited or killed by this concentration. These differences are significant $(P<0.01)$. In both series all strains were killed by 5 to $8 \mu \mathrm{g}$. of tetracycline per $\mathrm{ml}$.

TABLR III.-Summary of Studies of V. cholerae (Biotype El Tor, Ogazaa) Sensitivity to Tetracycline and Furazolidone. Minimum Inhibitory Concentration (M.I.C.) and Minimum Bactericidal Concentration Concentration (M.I.C.) and Minimum Bactericidal Concentration
(M.B.C.) of Tetracycline and Furazolidone are Presented for 22 Strains from Present Study. For Comparison Tetracycline Sensitivity of 77 Strains Isolated in 1964 is also Summarized

1967. Vibrio cholerae, El Tor, Ogawa (22 strains), present study

\begin{tabular}{|c|c|c|c|c|c|c|c|c|}
\hline & \multicolumn{7}{|c|}{ Antibiotic Concentration ( $\mu \mathrm{g} . / \mathrm{ml}$.) } \\
\hline & & 1.0 & 2.0 & 4.0 & 8.0 & 16.0 & $32 \cdot 0$ & $>32.0$ \\
\hline Tetracycline $\left\{\begin{array}{l}\text { M.I.C } \\
\text { M.B.C }\end{array}\right.$ & $\because$. & $\begin{array}{l}0 \\
0\end{array}$ & 17 & $\begin{array}{r}5 \\
15\end{array}$ & $\begin{array}{l}0 \\
0\end{array}$ & : & 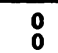 & 8 \\
\hline Furazolidone $\left\{\begin{array}{l}\text { M.I.C } \\
\text { M.B.C }\end{array}\right.$ & $\because$. & $\begin{array}{l}\mathbf{0} \\
\mathbf{0}\end{array}$ & $\begin{array}{l}\mathbf{0} \\
\mathbf{0}\end{array}$ & $\begin{array}{l}0 \\
0\end{array}$ & $\begin{array}{r}15 \\
0\end{array}$ & $\begin{array}{l}7 \\
0\end{array}$ & $\begin{array}{r}0 \\
14\end{array}$ & $\begin{array}{l}0 \\
8\end{array}$ \\
\hline
\end{tabular}

1964. V. cholerae, El Tor, Ogawa (77 strains) (Lewois and Sanyal, 1965)

\begin{tabular}{|c|c|c|c|c|c|c|}
\hline & & \multicolumn{5}{|c|}{ Antibiotic Concentration ( $\mu \mathrm{g} . / \mathrm{ml}$.) } \\
\hline & & 0.5 & $1 \cdot 0$ & $2 \cdot 5$ & $5 \cdot 0$ & $10-0$ \\
\hline Tetracycline $\left\{\begin{array}{l}\text { M.I.C. } \\
\text { M.B.C. }\end{array}\right.$ & $\because$ & $\begin{array}{l}\mathbf{0} \\
\mathbf{0}\end{array}$ & $\begin{array}{l}18 \\
20\end{array}$ & $\begin{array}{l}53 \\
42\end{array}$ & $\begin{array}{r}6 \\
15\end{array}$ & $\begin{array}{l}\mathbf{0} \\
0\end{array}$ \\
\hline
\end{tabular}

\section{Discussion}

The effectiveness of antibiotics as adjuncts to the treatment of cholera has been established by the reductions shown in total stool volume, duration of diarrhoea, and duration of detectable $V$. cholerae excretion following oral antibiotic administration. Tetracycline (Greenough et al., 1964 ; Wallace et al., 1965; Carpenter et al., 1966), chloramphenicol (Wallace et al., 1968 ; Lindenbaum et al., 1968), and streptomycin (Lindenbaum et al., 1968) have been shown to be effective. However, the demonstration of rapidly developing resistance of $V$. cholerae to streptomycin seems to limit its usefulness as a therapeutic agent (Lewis, 1967). Sulphaguanidine and paromomycin are of little or no value in the treatment of cholera (Lindenbaum et al., 1967 ; Wallace et al., 1968). Tetracycline has been recommended as the antibiotic of choice in cholera (Wallace et al., 1968).

Cholera vibrios (classical and $\mathrm{El}$ Tor biotypes) have been reported to be sensitive to furazolidone, and it has been suggested that this antibacterial agent is of value in the treatment of cholera (Chaudhuri et al., 1965, 1968 ; Kobari, 1965). The present study confirms its effectiveness in cholera, indicating that furazolidone, in either dosage schedule used, reduced total stool volume by about $50 \%$ and duration of diarrhoea by about $40 \%$, these results not differing significantly from those obtained with tetracycline given in the usually recommended dosage (4 g. total dose). The rates of decline in stool output after antibiotic therapy were also comparable with furazolidone and tetracycline, and with either drug were significantly greater than in controls. Furthermore, the time of onset of an effect on the rate of stool output was the same with fura- zolidone and tetracycline. With both agents a decrease in the rate of stool production attributable to antibiotic therapy was definitely present 18 to 24 hours after initiation of antibiotic treatment and may have begun as early as 6 to 12 hours after treatment. Recurrence of diarrhoea after termination of therapy was not noted with either antibiotic.

The results of treatment with tetracycline and furazolidone differed, however, in that detectable $V$. cholerae excretion was consistently reduced to less than two days with tetracycline but was only moderately reduced by furazolidone, lasting up to seven days in one patient. Prompt and consistent termination of $V$. cholerae excretion is a desired result of the antibiotic treatment of cholera, because it is possible that patients returning home still excreting cholera vibrios may contribute to further spread of the organisms in the community. Since the stay in hospital for treatment and control of the diarrhoea of cholera may usually be reduced to three days when effective antibiotic adjuncts are used, it is highly desirable that $V$. cholerae excretion be terminated within this period. This was accomplished with tetracycline but was not consistently achieved with furazolidone in either schedule used. We have therefore concluded that furazolidone is effective in the treatment of cholera but is inferior to tetracycline (when given in $4 \mathrm{~g}$. total dosage) because of its failure to achieve a comparable and consistent reduction in the duration of $\boldsymbol{V}$. cholerae excretion. Furazolidone appears to be comparable to tetracycline in regard to all other aspects of therapeutic effectiveness measured in this study.

The reliability of tetracycline in terminating $V$. cholerae excretion is borne out by our observations in 46 cholera patients during the past three years, which indicate that a total dose of 3-4 g. of tetracycline reduced vibrio excretion to a mean of 1.3 days and a maximum of three days. Lower doses of tetracycline ( $2 \mathrm{~g}$. total dose) have, however, been associated with prolonged $\boldsymbol{V}$. cholerae excretion in some patients and occasional relapse of diarrhoea (Wallace et al., 1965).

Though not compared in this study, furazolidone appears to be as effective as chloramphenicol (Lindenbaum et al., 1967 ; Wallace et al., 1968), which has been stated to be the alternative choice if tetracycline is not available or if clinically significant resistance of $V$. cholerae to tetracycline should occur (W.H.O., 1967). Like furazolidone, chloramphenicol has been inconsistent in shortening $V$. cholerae excretion (Lindenbaum et al., 1967, 1968), and occasional cases of prolonged excretion of cholerae vibrios after chloramphenicol have been reported (Gangarosa et al., 1966). In comparison with chloramphenicol furazolidone has the advantage of both lower cost and greater safety. Furazolidone has not been associated with serious sideeffects, whereas hypoplastic anaemia is known to follow chloramphenicol administration occasionally.

The 22 strains of $V$. cholerae tested from the present study were inhibited and killed by moderate concentrations of tetracycline $(2$ to $8 \mu \mathrm{g} . / \mathrm{ml}$.). These figures indicate only a slight decrease in sensitivity of $\mathrm{El}$ Tor biotype strains to tetracycline when compared with those isolated in Calcutta in 1964 (Lewis and Sanyal, 1965). Other reports indicate that significant resistance of cholera vibrios to tetracycline and chloramphenicol can be produced in vitro (Lewis, 1967) and that naturally resistant strains may occur. A small number of naturally occurring multiple-resistant strains of $V$. cholerae El Tor biotype have been isolated. One such strain had significant resistance to tetracycline $(100 \mu \mathrm{g} . / \mathrm{ml}$.) (J. Kuwahara, personal communication). These strains were also resistant to chloramphenicol, streptomycin, and sulphathiazole, and their resistance to all of these antibiotics was transferable to other enterobacteria and to sensitive strains of $V$. cholerae. The possible clinical significance of such transferable antibiotic resistance in cholera has not yet been clarified.

Sensitivity testing of strains from the present study indicate that larger concentrations of furazolidone are required to inhibit $V$. cholerae growth ( $\delta$ to $16 \mu \mathrm{g} . / \mathrm{ml}$.) than of tetracycline, and 
that killing of cholera vibrios in $36 \%$ of strains tested did not occur with concentrations approaching the limit of solubility of the drug in intestinal fluid $(40 \mu \mathrm{g} . / \mathrm{ml}$.). This failure to effect killing of cholera vibrio strains within easily achieved antibiotic concentrations offers a possible explanation of the longer period of cholera vibrio excretion observed after furazolidone than after tetracycline treatment. It is of interest that comparable reductions in stool volume and duration of diarrhoea were achieved by antibacterial agents which differed significantly in their ability to terminate cholera vibrio excretion. It is possible that both agents rapidly reduce or inhibit the growth of the intestinal $V$. cholerae population and reduce the production of the cholera exotoxin responsible for the continuation of diarrhoea. However, tetracycline, which is vibriocidal, may rapidly carry this process to complete $V$. cholerae elimination, whereas furazolidone, which is not consistently vibriocidal in the concentrations probably achieved, may require host defence mechanisms to effect complete elimination of cholera vibrios.

Purging of convalescent cholera patients with magnesium sulphate has been used to detect prolonged carriers of cholera vibrios, which are not detectable by the culture of rectal swabs (Gangarosa et al., 1966 ; Wallace et al., 1967). Of 43 patients so purged in this study one from the control group was identified as a convalescent carrier of cholera vibrios. In the past two years five such prolonged convalescent carriers have been identified by this unit (Wallace et al., 1967). Three of these had received no antibiotic treatment, one had received initial treatment with furazolidone ( $200 \mathrm{mg}$. every six hours) for two days only (not included in this study), and one received tetracycline (500 mg. every six hours) for two days, beginning on the fourth day of illness. Though tetracycline (4 g. total dose) clearly shortens the duration of detectable $V$. cholerae excretion in most patients it is not yet certain that antibiotics reduce the incidence of the prolonged cholera vibrio carrier state detected in about $3 \%$ of convalescent patients examined by this unit.
The large dosage of furazolidone used in this study was chosen to demonstrate maximal drug effect. The $1.2 \mathrm{~g}$. schedule was as effective as the $2.4-\mathrm{g}$. schedule. It is probable that a schedule of $100 \mathrm{mg}$. every six hours for three days $(1.2 \mathrm{~g}$.) would be as effective as either schedule studied and might be associated with a lower incidence of vomiting, the only sideeffect noted.

We wish to express our appreciation of the co-operation and assistance given by Dr. P. M. Manji, Superintendent of the Infectious Diseases Hospital, and Dr. J. B. Chatterjea, Director of the School of Tropical Medicine, Calcutta.

\section{REFERENCES}

Barua, D., and Mukherjee, A. C. (1963). Bull. Calcutta Sch. trop. Med., $11,85$.

Carpenter, C. C. J., et al. (1966). Bull. Johns Hopk. Hosp., 118, 216.

Chaudhuri, R. N., Neogy, K. N., Sanyal, S. N., Gupta, R. Ü., and Manji, P. (1968). Lancet, 1, 332.

Chaudhuri, R. N., Sanyal, S. N., Neogy, K. N., Barua, D., and Manji, P. (1965). Lancet, 2, 909.

Gan, K. H., and Tija, S. K. (1963). Amer. F. Hyg., 77, 184.

Gangarosa, E. J., Saghari, H., Emile, J., and Siadat, H. (1966). Bull. Wld Hlth Org., 34, 363.

Greenough, W. B., Gordon, R. S., Rosenberg, I. S., Davies, B. I., and Benenson. A. S. (1964). Lancet, 1, 355.

Kobari, K. (1965). Proceedings of Cholera Research Symposium, edited by O. A. Bushnell and C. S. Brookhyser, p. 199. Washington.

Lewis, G. W. (1967). Clin. Res., 15, 426.

Lewis, G., and Sanyal, S. (1965). Bull. Calcutta Sch. trop. Med., 13, 40 indenbaum, J., Greenough, W. B., and Islam, M. R. (1967). Bull. Wld Hith Org., 36, 871 .

Lindenbaum, J., Greenough, W. B.,, and Islam, M. R. (1968). Bull. Wld Hlth Org. In press.

Mukherjee, S., Guha, D. K., and Guha Roy, U. K. (1957). Ann. Biochem., 17, 161 .

Wallace, C. K., et al. (1965). Trans. roy. Soc. trop. Med. Hyg., 59, 621. Wallace, C. K., et al. (1967). Lancet, 1, 865.

Wallace, C. K., et al. (1968). Bull. Wld Hlih Org. In press.

W.H.O. Expert Committee on Cholera (1967). Wld Hlth Org. techn. Rep. Ser., No. 352, Second Report, p. 18.

\title{
Immunological Aspects of Intrauterine Transfusion
}

\author{
W. R. JONES,* M.B., B.S., M.R.C.o.G.
}

Cummary : Two cases of intrauterine transfusion were $\checkmark$ studied with reference to the viability and fate of donor lymphocytes. In one of the infants donor lymphocytes were found in cord blood in significant numbers, suggesting the presence of a degree of immunological tolerance. Though lymphocyte chimerism may occur after foetal transfusion, the absence of associated graftversus-host reactions in the great majority of babies so treated implies that an immunological protection mechanism develops by at least the second half of gestation.

Cord serum immunoglobulins were normal in both cases except for the presence of IgA, presumably due to the passive transfer of donor protein.

The opportunity afforded by intrauterine transfusion for the study of foetal immunology is stressed. It is suggested that, in our present state of knowledge and in view of the small risk of graft-versus-host reaction, such studies should have precedence over efforts to remove immunologically active cells and protein from transfusion blood, especially since such efforts may impair the efficacy of the procedure.

- Department of Obstetrics and Gynaecology, University of Leeds. sity of Sydney.
sitent address

\section{Introduction}

Intrauterine transfusion is now widely used in severe rhesus isoimmunization (Liley, 1963 ; Lucey and Butterfield, 1966). Interest has recently been aroused in the possible immunological effects of this procedure on the foetus (Hrushovetz, 1965; Githens, 1966) and in the valuable opportunity it affords for the study of foetal immune reactions (Sterzl and Silverstein, 1967 ; Jones, 1967a). This paper describes a study of two cases of intrauterine transfusion and reviews the immunological implications of the procedure.

\section{Material and Methods}

Two babies were investigated for the persistence into postnatal life of lymphocytes from donor blood. The sex of the foetus was determined before transfusion by sex chromatin analysis of amniotic fluid squames (Coulson and Scott, 1967). Opposite sex donor blood was then used for each transfusion in that particular foetus. The transfusion blood varied in age from three to four days. It was citrated and packed to a haematocrit of $60 \%$. At delivery umbilical cord blood was collected for chromosome analysis and immunoglobulin estimation. 